\title{
Brain Abscess and Esophageal Dilatation: Where is the Link? - Case Report
}

\section{Abcesso cerebral e dilatações esofágicas: Qual a relação? - Relato de caso}

\author{
Leonardo C. Welling ${ }^{10}$ Fabricio Stewan Feltrin ${ }^{2(}$ Mariana S. Welling ${ }^{3}$ João Afonso Caldeira Brino ${ }^{2(0)}$ \\ Victor Feferbaum Zyto ${ }^{4}$ Eberval G. Figueiredo ${ }^{50}$ \\ ${ }^{1}$ Neurological Surgery Department, Universidade Estadual de Ponta \\ Grossa, Ponta Grossa PR, Brazil \\ 2 Radiology Department, Universidade Estadual de Ponta Grossa, \\ Ponta Grossa, PR, Brazil \\ ${ }^{3}$ Neurology Department, Universidade Estadual de Ponta Grossa, \\ Ponta Grossa, PR Brazil \\ ${ }^{4}$ Pediatric Surgery Department, Universidade Estadual de Ponta \\ Grossa,Ponta Grossa, PR, Brazil \\ ${ }^{5}$ Neurological Surgery Department, Universidade de São Paulo, São \\ Paulo, SP, Brazil \\ Arq Bras Neurocir 2020;39(2):146-148.
}

\section{Abstract \\ Keywords \\ - brain abscess \\ - esophageal stenosis \\ - endoscopy}

\section{Resumo}

received

September 29, 2019

accepted

December 11, 2019
Introduction Caustic substance ingestion is a common cause of esophageal stricture in children. The primary treatment is esophageal dilatation. Although it is known that endoscopic esophageal dilatation is a procedure associated with a high rate of bacteremia, current guidelines do not recommend routine throat swab cultures or antibiotic prophylaxis for the general children population.

Case Report We describe a case of a 7-year-old boy presenting with refractory headaches who was diagnosed with cranial abscess after multiple esophageal dilatations due to stenosis caused by caustic soda ingestion. The patient was subjected to neurosurgical intervention and intravenous antibiotic treatment for 6 weeks. Streptococcus viridans culture was positive in purulent abscess content.

Conclusion We highlight this condition that, although rare, needs immediate diagnosis and proper treatment. We also recommend routine testing of throat swabs and antibiotics prophylaxis to children undergoing esophageal dilatation.

Introdução A ingestão de soda cáustica é uma causa comum de estenose esofágica em crianças. O tratamento principal é a dilatação esofágica. Apesar de a dilatação esofágica endoscópica ser um procedimento sabidamente associado a altos índices de bacteremia, as diretrizes atuais não recomendam culturas de swabs da garganta ou antibioticoprofilaxia de rotina para a população pediátrica em geral.

Relato do caso Descrevemos o caso de um menino de 7 anos de idade apresentando cefaleia refratária, o qual foi diagnosticado com abscesso cerebral após múltiplos procedimentos de dilatação esofágica para o tratamento de estenose esofágica causada por ingestão de soda cáustica. O paciente foi submetido a intervenção 


\section{Palavras-chave}

- abscesso encefálico

- estenose esofágica

- endoscopia neurocirúrgica e antibioticoterapia endovenosa por 6 semanas. A cultura do material purulento do abscesso cerebral foi positiva para Streptococcus viridans.

Conclusão Destacamos essa condição que, apesar de rara, necessita diagnóstico imediato e tratamento adequado. Recomendamos também a coleta de swabs da garganta de forma rotineira bem como antibioticoprofilaxia para crianças que serão submetidas a dilatações esofágicas.

\section{Introduction}

Caustic substance ingestion is a common cause of esophageal stricture in children. ${ }^{1}$ The primary treatment is esophageal dilatation. ${ }^{1}$ Esophageal dilatation is associated with complications such as perforation, hemorrhage, and mediastinal abscesses. Occurrence of abscesses in distant organs, including the brain, is rare but an important and fatal complication. ${ }^{2}$ Streptococcus viridans is the predominant species associated with bacteremia following esophageal dilatation. ${ }^{2}$ Bacteremia associated with endoscopic dilatation was detected only in patients presenting esophageal strictures. ${ }^{3}$ Its onset is subtle and depends largely on clinical awareness of this condition. ${ }^{2}$ Current guidelines do not advocate routine use of antibiotic prophylaxis preceding esophageal dilatation. We report a case of this complication after multiple endoscopic esophageal dilatations were performed in order to treat strictures caused by caustic soda ingestion in a child. We emphasize a rare but potentially fatal complication in a relatively common scenario that requires attention to the often unspecific symptoms and their relationship to endoscopic procedures, highlighting esophageal dilatation, which is known to be related to higher rates of bacteremia.

\section{Case Report}

A 7-year old male patient presented with severe headache refractory to conventional analgesic treatment 15 days prior hospitalization. Only one episode of fever has been reported. No focal neurologic deficit or signs of meningism were evident on neurologic examination. Laboratory examination was essentially normal. The patient had a history of ingestion of caustic soda one year previously. He had been treated over the previous year with esophageal endoscopic dilatation, done four times without any complications reported. None of the endoscopic interventions had received antibiotic prophylaxis and neither the throat culture swab was collected. A computed tomography (CT) scan was performed and demonstrated a right lobe hypodense lesion with contrast enhancement that was further evaluated by a magnetic resonance image (MRI) of the brain. This revealed a lesion on the right frontal lobe characterized by necrotic center, peripheral rim of enhancement and extensive area of vasogenic edema compatible with brain abscess (-Fig. 1 and -Fig. 2). He was subjected to emergency surgical intervention to remove the brain abscess. The culture of the material showed presence of $S$, viridans. Blood culture was negative.
He was also treated with intravenous antibiotics for 6 weeks and then discharged without any neurological deficits.

\section{Discussion}

The reported incidence of transient bacteremia following endoscopies and colonoscopies is $<5 \%{ }^{3}$ However, its incidence is much higher following endoscopic dilatation procedures, with some authors reporting occurrence of $100 \%$ transient bacteremia. ${ }^{3,4}$ The occurrence of brain abscess after esophageal dilatation is sporadic, with literature reports of only 8 cases in the pediatric population. ${ }^{5}$ Zuccaro et al demonstrated that blood cultures obtained 1 minute after stricture dilation were positive for S. viridans in $23 \%$, in $17 \% 5$ minutes postdilation, and in $5 \% 30$ minutes postdilation. In patients with $S$. viridans bacteremia 1 minute after dilation, cultures were still positive in $74 \%$ at 5 minutes and in $10 \% 20$ to 30 minutes postdilation. ${ }^{6}$ Besides, it was also observed that patients with severe strictures, in whom the

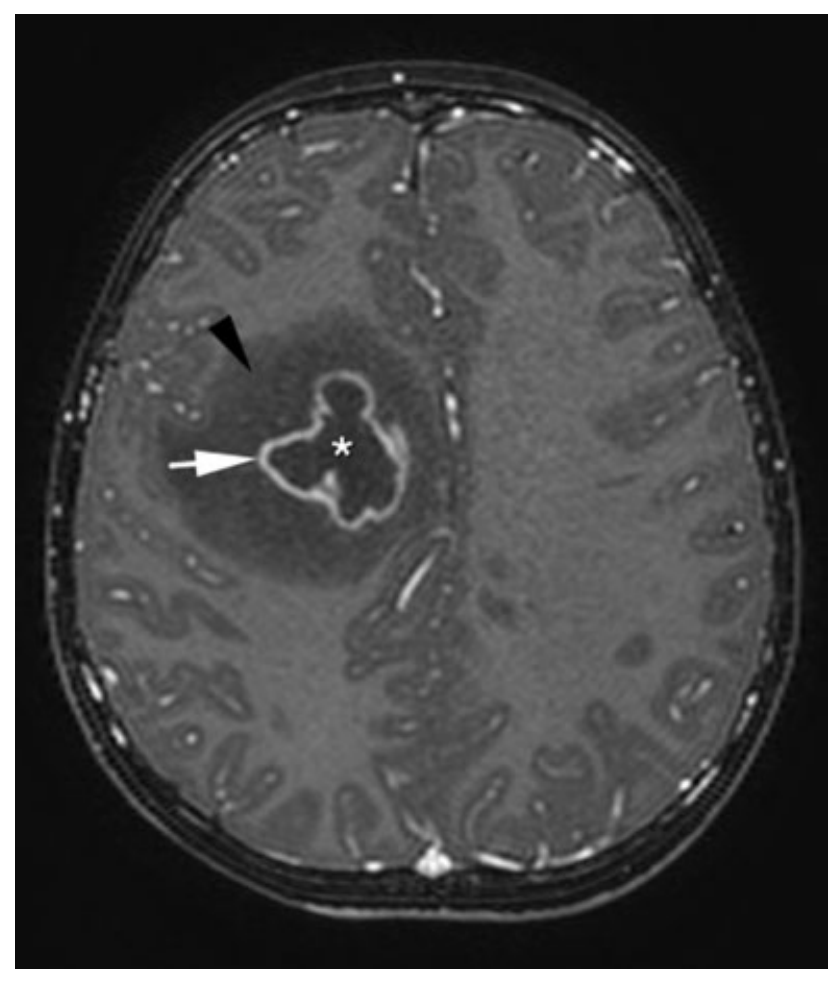

Fig. 1 Magnetic Resonance Image. T1 sequence with gadolinium. Central low signal intensity (hypointense to CSF) - asterisk. Peripheral low intensity (vasogenic edema) - black arrow. Ring enhancement white arrow. 


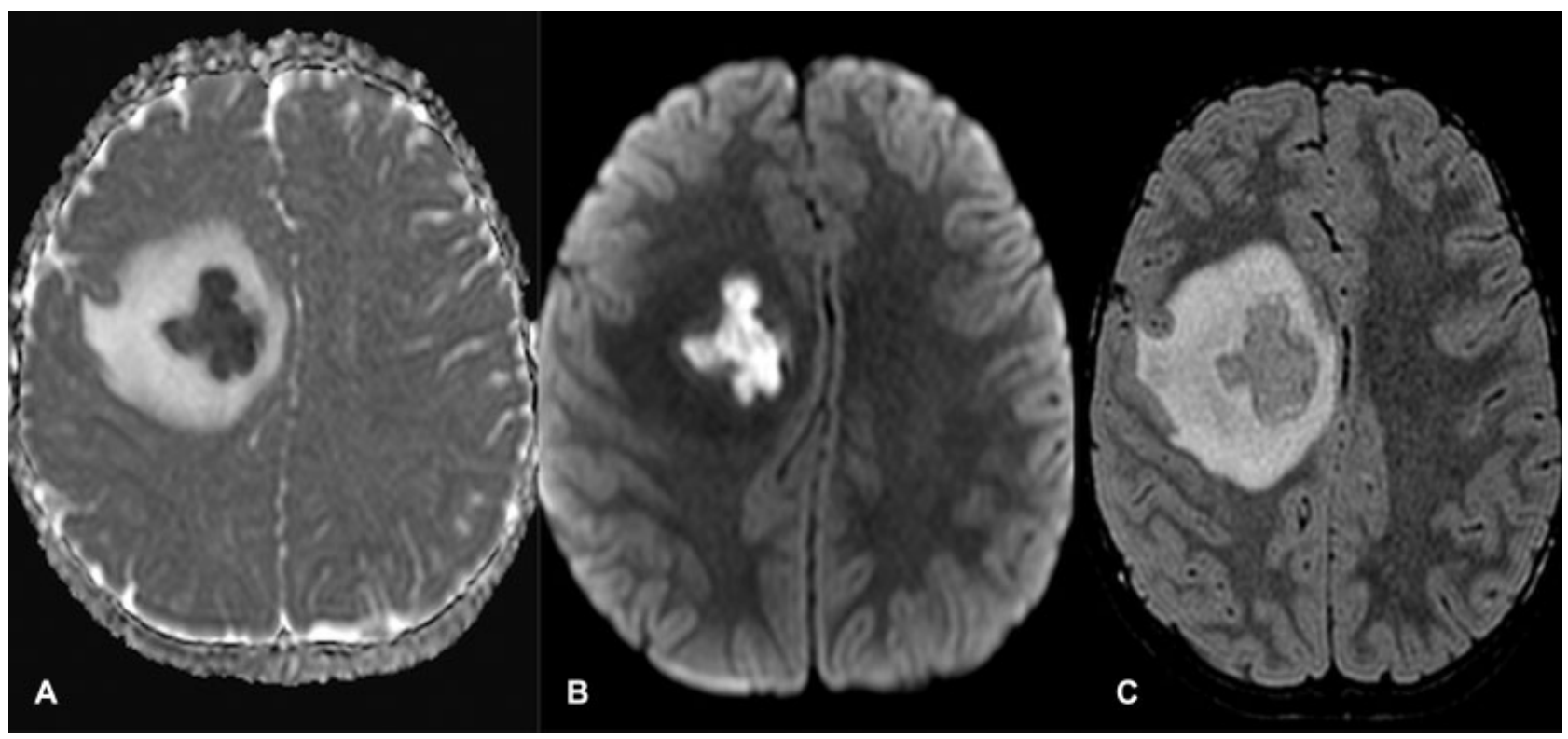

Fig. 2 Magnetic Resonance Image. Low ADC values (2A) and high signal in diffusion sequence (2B) in the necrotic core are the hallmarks of the brain abscess, representing thick inflammatory liquid. The FLAIR sequence clearly depicts a hyperintense halo representing extensive vasogenic edema, also a classic feature of brain abscesses (2C).

endoscope could be passed with difficulty, the incidence of bacteremia was higher. Streptococcus viridans infection is associated to suppurative abscess mainly in abdominal viscera and in the brain. ${ }^{2}$ Although there is no doubt with regards to antibiotic prophylaxis in children with cardiac problems, its role in the general child population is controversial. Some predisposing factors of brain abscess development are contiguous focus of infection, head injury, and hematogenous spread from a distant focus. ${ }^{1}$ In order to decrease the frequency of bacteremia following esophageal dilatation, it is recommended to collect throat swabs on the admission to determine the sensitivity profile of the flora and culture of the patient to guide appropriated antibiotic prophylaxis. ${ }^{2}$ It is also suggested endoscopic lavage with antiseptic solution or saline solution preceding the procedure. ${ }^{5}$ Hofmeyr et $\mathrm{l}^{2}$ also suggest that this complication should be included in the informed consent given to patients undergoing esophageal stricture dilation. Brain abscesses in patients undergoing esophageal dilatations may be potentially fatal unless diagnosed and treated properly. ${ }^{1}$

\section{Conclusion}

Considering the rarity of this complication after endoscopic procedures, there is a paucity of evidence for routine use of antibiotic prophylaxis. We would recommend a routine determination of the throat commensal flora and its sensitivity and the use of antibiotic prophylaxis in patients undergoing esophageal dilatation especially in the pediatric age group, as there are no surrogate signs to provide evidence that a child may develop an intracranial abscess.

\section{Conflict of Interests}

The authors have no conflict of interests to declare.

\section{References}

1 Erşahin Y, Mutluer S, Çakir Y. Multiple brain abscesses following esophageal dilation. Childs Nerv Syst 1995;11(06):351-353

2 Hofmeyr S, Sidler D, Moore SW. Multiple Streptococcus milleri cerebral abscesses after repeated esophageal caustic stricture dilation. J Pediatr Surg 2008;43(05):964-966

3 Botoman VA, Surawicz CM. Bacteremia with gastrointestinal endoscopic procedures. Gastrointest Endosc 1986;32(05):342-346

4 Yin TP, Ellis R, Dellipiani AW. The incidence of bacteremia after outpatient Hurst bougienage in the management of benign esophageal stricture. Endoscopy 1983;15(05):289-290

5 Aslan N, Sesli E, Koca T, Senol N, Akcam M. A rare complication of esophageal dilatation: Brain abscess. Türk Pediatr Arşivi. 2017

6 Zuccaro G Jr, Richter JE, Rice TW, et al. Viridans streptococcal bacteremia after esophageal stricture dilation. Gastrointest Endosc 1998;48(06):568-573 